\title{
Science initial teacher education and superdiversity: educating science teachers for a multi- religious and globalised science classroom
}

\section{Roussel De Carvalho}

Published online first on 11/01/16

The final publication is available at :

\section{Cultural Studies of Science Education: DOI 10.1007/s11422-015-9671-y}

\begin{abstract}
:
Steven Vertovec $(2006,2007)$ has recently offered a re-interpretation of population diversity in large urban centres due to a considerable increase in immigration patterns in the UK. This complex scenario called superdiversity has been conceptualised to help illuminate signifi- cant interactions of variables such as religion, language, gender, age, nationality, labour market and population distribution on a larger scale. The interrelationships of these themes have fundamental implications in a variety of community environments, but especially within our schools. Today, London schools have over 300 languages being spoken by students, all of whom have diverse backgrounds, bringing with them a wealth of experience and, most critically, their own set of religious beliefs. At the same time, Science is a compulsory subject in England's national curriculum, where it requires teachers to deal with important scientific frameworks about the world; teaching about the origins of the universe, life on Earth, human evolution and other topics, which are often in conflict with students' religious views. In order to cope with this dynamic and thought-provoking environment, science initial teacher education (SITE) - especially those catering large urban centres - must evolve to equip science teachers with a meaningful understanding of how to handle a superdiverse science classroom, taking the discourse of inclusion beyond its formal boundaries. Thus, this original position paper addresses how the role of SITE may be re-conceptualised and re-framed in light of the immense challenges of superdiversity as well as how science teachers, as enactors of the science curriculum, must adapt to cater to these changes. This is also the first in a series of papers emerging from an empirical research project trying to capture science teacher educators' own views on religioscientific issues and their positions on the place of these issues within science teacher education and the science classroom.
\end{abstract}

\section{Science and superdiversity}

Recently, Steven Vertovec (2006, 2007) offered a re-interpretation of population diversity in large urban constituencies due to a considerable increase in immigration patterns, especially within the UK. This scenario, dubbed superdiversity, has been conceptualised to help illuminate the significant and complex interactions of variables such as religion, language, gender, age, nationality, labour market and population distribution on a larger scale. The interrelationships between these themes have fundamental implications in a variety of community environments, but especially within our schools. Today, for example, London state schools have over 300 languages spoken (Von Ahn, Lupton, Greenwood and Wiggins 2010) by their students, all of whom have their own particular 
cultural background, bringing with them a wealth of experience and, most critically, their own set of religious or non-religious beliefs, worldviews and indigenous knowledge.

Science is a compulsory subject in England's National Curriculum where it requires students to obtain key scientific knowledge and understanding about the world we live in: the origins of the universe, geological time radioactive dating, fossils, life on Earth and human evolution are some of the most critical examples. Notably, these central themes within the science curriculum are often complex constructs which have been built over years of methodical research and scientific testing of theoretical frameworks. Consequently, in order to fully understand these constructs, a fundamental understanding of the variances and nuances of the scientific method and the meaning of evidence must be one of the central tenets of science education within the secondary school.

\section{Science and worldviews}

The complex constructs mentioned above often sit in a continuous spectrum of acceptanceopposition, particularly in those individuals with religious views (Roth 1997) and indigenous knowledge (Waldrip, Timothy and Wilikai 2007) as well as those who are atheists and anti-theists (Dawkins 2006). Hence, it becomes imperative to recognise that those involved within the science education community-such as teacher educators, preservice teachers and teachers-are likely to belong to multifaceted cultural groups and have developed their own understandings of the world. Therefore, when these actors are necessarily placed within social learning environment, these intrinsic understandings are likely to influence their teaching and learning practices and how they interact with school students. This is because science teachers and students have their own customs, principles, belief systems, desires and expectations (Aikenhead 1996) which may need to be rearranged and re-interpreted when dealing with conflicting 'believing schemas' (Ferguson and Kameniar 2014).

As such, these differing worldviews - defined as "a collection of values and beliefs that forms the frame of reference for a group of people to make sense of the world" (Kawagley et al. 1998 in Liu and Lederman 2007, p. 1283)-are likely to emerge within the science classroom when dealing with certain aspects of the science curricula, especially because "science students are expected to construct scientific concepts meaningfully even when those concepts conflict with indigenous norms, values, beliefs, expectations, and conventional actions of students' life-worlds" (Aikenhead and Jegede 1999, p. 270).

At the same time, science can also be considered a worldview since it is made up of models constructed by humans for problem solving and adapting to their environment. We have created codes and languages to organise our knowledge gained by observing Nature. Science is at its core a human activity and as such, it gives rise to ethical, epistemological and philosophical issues (Newton 1988) on how it operates and how it is disseminated. It is this way of working which attracts many different types of people into the scientific endeavour. Moreover, it is important to note that many people with a religious faith are still drawn to science and science education, mainly because they do not perceive there to be any challenges between their beliefs and what they are learning. On the other hand, Joseph Ferguson and Barbara Kameniar (2014, p. 19) suggested that:

Religious students of science are unlikely to be deeply engaging with science as a discipline when ... they employ a binary cultural model that subordinates science to religion, non- 
humans to humans and learning to believing... [and] because these religious students do not conceptualise meaningful learning as knowledge production, that is a justified belief with substantiated evidence, then learning for them remains a narrative to be reproduced or retold rather than as a process, or method, for seeking knowledge about, and an understanding of, the natural world.

As explained above, it is this binary model of science and religion with the contrasting narrative of science learning as either being for reproduction of knowledge or as a process of knowledge production that will likely be present within superdiverse science classrooms. It is the confluence of a range of interpretations and views about the world which have the potential to cause attrition, requiring careful mediation, as well as an opportunity for meaningful learning about science and its processes. However, this mediation will only occur if science teachers are fully prepared to engage with multiple worldviews and discourses in their classrooms.

\section{Bringing knowledge together}

Importantly, the point is not for science teacher educators, pre-service teachers and teachers to directly address specific religions and their beliefs. One of the argument being proposed here asks those involved in science initial teacher education (SITE) to support science pre-service teachers and science teachers by addressing the idea that there are different ways of looking at the world. People have different worldviews, of which science and/or religion and/or indigenous knowledge is one. The point is to address a broader cultural shift that needs to take places within science education. There is an increasing need for science teacher educators to support their pre-service teachers in learning about how they can support a superdiverse, multi-religious classroom to understand how science works regardless of where in the acceptance-opposition spectrum they fall. At the same time, science teachers must recognise their own worldview, their own epistemological and cultural understanding of science and develop their own acceptance of other worldviews in order to successfully teach their students about science, its accomplishments and its way of understanding the world.

This type of thinking has a direct implication for SITE because it asks teacher educators to be open to the notion that this preparation is both valid and necessary. Ignoring the reality science pre-service teachers will face during their training and later as fully-fledged science teachers would be a disservice to a community that needs students from all backgrounds to be inspired by science and to want to become scientists regardless of their cultural and religious beliefs. Thus, it becomes imperative that science teacher education programmes spend time helping pre-service teachers develop a meaningful understanding of science epistemology and philosophy because this will allow them to fully engage with pedagogical ideas of how science teaching may be conceptualised for their own school context.

At the same time, school students must be prepared to engage in these discussions. This implies that teachers must also learn how to create a safe classroom environment where their students are able to freely and politely exchange their thoughts and ideas about the world they live in. Undoubtedly, there will be intrinsic challenges that may cause a substantial impact on how science lessons are 
introduced in school and how it is perceived by students whose views may contradict a more traditional view of science (Liu and Lederman 2007). A clear example of this is in:

the USA [which] has had several decades of legal battles about the place of creationism and (more recently) intelligent design in schools (Moore, 2007), [and] school-based conflicts over these issues are becoming more frequent in a range of other countries (Graebsch and Schiermeier, 2006; Chinsamy and Plaga'nyi, 2007; Mercer, 2007; Kutschera, 2008).

(Reiss 2011, p. 400)

This diverse nature of worldviews also brings a new variety of both language and culture which have been argued to affect the way students may perceive science (Sutherland and Dennick 2002). Furthermore, current conceptual tools which have been applied within many schools have led to a comparative and binary construction of classroom reality (Gogolin 2011), i.e. higher vs lower ability, academic vs vocational, girls vs boys, believer vs non-believer, and these dichotomies should no longer be considered acceptable as an initial standpoint especially when dealing with a superdiverse classroom. This prejudiced rhetoric has the potential to cause even more student disaffection towards science education because it implies it is not for everyone. Meanwhile, superdiversity has caused a fundamental change that will have a significant impact on "how and with whom people teach and learn ..., consequently, [certain] measures aiming to adjust schools to the superdiversity ... must be taken up with regard to [the knowledge] structure as well as teaching practice" (Gogolin, p. 241).

\section{Science education and religious superdiversity: What do we know?}

In order to cope with this dynamic and critical scenario, SITE-especially when catering for large urban constituencies-must evolve to equip pre-service science teachers with a meaningful understanding of how to handle a superdiverse science classroom, taking the discourse of inclusion beyond its formal boundaries. When looking at the domain of science teaching, it is full of anecdotal stories about teacher-student and student-student interactions about their views and relationships between science, culture and religion.

The existing literature has attempted to research some of these conflicts. In the case of evolutionary biology, Zoubeida Dagher and Saouma Boujaude (1997, p. 441) investigated college students in Lebanon and concluded that "efforts are not likely to affect major cognitive differences in students without actively engaging-neither ignoring nor fighting-other factors that underlie their resistance to the ideas about evolution". On the same topic, Roger Downie and N. Barron (2000) have researched medical students in Scotland where $10 \%$ of students did not accept that evolution has occurred. Additionally, Pratchayapong Yasri and Rebecca Mancy (2014) investigated views of students in a Christian high school in Thailand. They argue that "students holding different positions on the relationships between science and religion engage with learning about evolution in different ways" (p. 40). Likewise, the study undertaken by Ferguson and Kameniar (2014) with religious students of science in Australia reaches a very similar conclusion.

These studies make a vital contribution to the practice of SITE since in order to negotiate meaning with school students holding different worldviews, science teachers (and pre-service teachers) must understand how these worldviews operate as well as their meaning within students' lives. 
Significantly, science teacher educators must also clearly understand their own worldviews and those of their pre-service teachers, enabling an open and constructive dialogue to emerge in order to support their training when dealing with contentious religio-scientific issues in the classroom. Studies have also been undertaken with students from different religious backgrounds including their views on the origins of the universe (Hanley, Bennett and Ratcliffe 2014), the compatibility of science and religion (Loving and Foster 2000) and the conflict between science and religion (MartinHansen 2008). On the other hand, Michael Reiss (2011) addresses the controversial issue of dealing with creationism and intelligent design in the classroom while Keith Taber, Berry Billingsley, Fran Riga, and Helen Newdick (2011) investigated 12-14 year-olds in secondary schools in England and their worldviews on the relationships between science and religion. They have identified that students

who experience some science teaching as contrary to their religious faith ... is potentially likely to negatively influence student learning, aspirations toward scientific study and careers, and level of confidence in scientific knowledge.

School teachers have also been the centre of many studies. The work of Pierre Clement, Marie Quessada, Charline Laurent and Graca Carvalho (2008) analysed the conceptions about science and religion of over 5000 teachers from 14 different countries, highlighting not only the presence of religious convictions in teachers but also the intrinsic differences between them as well as the importance of the need of teacher education to address misunderstandings between science and religion. More specifically, Jeff Dodick, Aliza Dayan and Nir Orion (2010) examined issues that "religious Jewish science teachers in Israeli high schools have in coping with science subjects (such as geological time) which conflict with their religious beliefs" (p. 1521). They also point out that teachers have a lack of a consistent philosophy (and I would argue, epistemology) and thus adopted intuitive and haphazard approaches and explanations which used both science and religion help them cope. Further still, protestant biology teachers in Brazil are the focus of the work of Charbel ElHani and Claudia Sepulveda (2010) which concludes by indicating the need for science teachers to be more philosophically and culturally aware of the issues between science and religion. More important evidence is present in the work of Nasser Mansour (2008) which has been crucial in giving emphasis to the fact that 'teachers' religious beliefs are among the major constructs that drive teachers' ways of thinking and classroom practices about scientific issues related to religion" (p. 557) and has been corroborated by his further work (Mansour 2011) with Egyptian science teachers where "teachers' personal Islamic religious beliefs inform their beliefs about the nature of science and its purpose" (p. 281).

Additionally, Reiss (2008) tries to answer the question of whether science teacher educators should deal with the Science/Religion issue and delves into a critical reflection of the current literature. Reiss argues that science teachers should not ignore the issue and must be careful as to how this is dealt with in the classroom. But in order for teachers to be careful and handle a superdiverse and multi-religious classroom, it is important that they understand their own worldviews and have a good understanding of the nature of science. And this can only be achieved if SITE allows time for such discussions in science teacher education programmes.

The work of Shiang-Yao Liu and Norman Lederman explores this. Their work argues that: 
People with different worldviews may probably have concurrently different views about science; such differences need to be acknowledged and incorporated into science curriculum. The findings showed that participants held diverse views, some of which did not accord with the worldview generally conveyed by western culture.

(2007, p. 1301)

When these views are in conflict with the nature of science, some science teachers even refuse to teach about what might be considered a controversial topic, such as evolution. For example, Randi Trani's work on biology teachers from Oregon, USA, finds that up to $16 \%$ of

biology teachers ... do not understand science, do not understand evolution, and have either strong or extreme religious convictions. These teachers may state that they reject evolution based upon their religious convictions, but their rejection of the evolutionary theory appears to also be related to their lack of understanding of the theory itself and their lack of understanding of the nature of science

(2004, p. 426).

More recently, Berry Billingsley, Fran Riga, Keith Taber and Helen Newdick (2014) have extensively discussed the literature on the science and religion debate and researched science and religious education teachers' perspectives on the matter. In the case of science initial teacher education, they recommend the "need for a higher level of subject knowledge about the relationships between science and religion and also more pedagogical knowledge about what children are expected to know" (p. 391). In order for such recommendation to take place, science teacher educators must be willing to drive this change within their institutions and provide opportunities for discussion on this highly important and, at times, contentions topic.

Lastly, the evidence collected from the academic literature presented above is an invitation to the development of this important area of study that certainly deserves our attention, especially in environments considered to be superdiverse. The works mentioned above are the foundation with which to develop this study because there has not as yet been enough research undertaken in order to provide a consistent argument about how England's SITE should be re-framed in light of superdiversity within schools and their local communities, particularly those placed in large urban centres such as London, Manchester and Birmingham. Given the evidence presented above, this position paper attempts to address how the role of SITE may need to be re-conceptualised and reframed in light of the immense challenges of superdiversity, as well as how science teacher educators must adapt to cater for these changes.

\section{Engaging with the issues}

Science teachers face several challenges during their careers, especially since science is usually seen as a 'hard' subject, with its own characteristic language, meaning and conceptual problems (Wellington and Osborne 2001). Furthermore, science teachers have an extensive assortment of issues to address within the classroom, mainly regarding the nature and application of science (Bausor and Poole 2003) as well as dealing with ideas such as scientific investigations and evidence, especially, in England, due to the recommendations that emerged from the new 'Working Scientifically' strand of the National Curriculum (DfE 2013) and the 'Maintaining Curiosity' report 
from the Office for Standards in Education and Children's Services (OFSTED) (OFSTED 2013). But as the science classroom becomes a more heterogeneous environment in relation to the composition of students' worldviews, and, in particular, their religious beliefs, a critical scenario emerges because such views are likely to fall within a 'spectrum of belief' within students' denominations. This "religious superdiversity has ramifications ... [where people find themselves] in such a situation of overlapping diasporas that [students and teachers] will meet ... other believers [and non-believers] who have different modes of belief and practice[s] both within and outside [their faiths]" (Vertovec 2006, p. 12) and, therefore, they will need to interact with religio-scientific discourses in light of their beliefs within the science classroom.

Glen Aikenhead (1996) argues that school science is a unique culture and a subculture of science. However, although some may perceive science to be a cultural norm in the western world, school science is usually presented as a-cultural and emotionless (Alsop 2005), especially in England where the science national curriculum continues to be mostly presented as a continuous sequence of factual knowledge usually taught without an historical or cultural context. There are many reasons for this. Evidence from national reports (Collins, Reiss and Stobart 2009) and news media outlets (BBC 2008, The Guardian 2006, Daily Telegraph 2008, 2010) have claimed that schools break down lessons in chunks of 50-60 min burst of information, they have reduced science practical work time and regurgitate standard explanations which students are expected to recall in exams.

Unfortunately, this continues to happen today, even though this 'teaching to the test' has already been shown to be highly inefficient in terms of learning outcomes for students (e.g. Shepherd 2010). Occasionally certain important scientific figures may be mentioned by name, but almost always they are insulated from the 'when' (historical context), the 'how' (personal context) and the 'why' (cultural/economic context) of their accomplishments. This rhetoric of 'imparting knowledge' as the function of school was reinforced by England's former Secretary of Education Michael Gove when he criticised:

teaching methods which have nothing to do with passing on knowledge ... We need teachers to actively pass on knowledge, organised in academic disciplines such as physics and history.

(Gove 2013, my emphasis)

The discourse towards a strong classification of curricula and pedagogy as discussed by Basil Bernstein (1971), is firmly implied in Gove's speech. Current curriculum changes imposed by England's Department for Education mean that students with different cultural and religious beliefs are likely to continue to view science as a disconnected bundle of facts and an intrusion on their worldview and their personal interest rather than a part of their own culture. The political rhetoric continues to focus on acquisition of formal knowledge through transmission, and it actively distances itself from other forms of pedagogical understanding of how children learn.

Moreover, this rhetoric continues to exist as cultural paradigms within many science classrooms where science is conceived as superior knowledge and disconnected from reality and where teaching towards examinations is commonplace. This is specially problematic where practical work is used and seen as only the checking of existing knowledge and the proving of equations rather than supporting students' comprehension of the place of science within the world and how science knowledge is constructed. This is because practical work "as practised in many countries, it is illconceived, confused and unproductive. For many children, what goes on in the laboratory 
contributes little to their learning of science" (Hudson p. 176, in Millar and Abrahams 2009, p. 59); a similar conclusion was also reached by the recent SCORE (2008) report on the use of practical work in schools.

Consequently, for students holding different worldviews, this conceptualisation of science teaching is potentially challenging as they continue to be constantly shifting between the language of science, religion and other subjects and cultures when moving from class to class and from home to school. This type of 'border-crossing' (Phelan, Davidson and Caon 2001) must be carefully managed within the curriculum (Aikenhead and Jegede 1999) as well as by class teachers and their students (Ferguson and Kameniar 2014).

The argument again returns to the need for an updated vision for SITE where future teachers are prepared to deal with personal conflicts and make pedagogical sense of the underlying and sometimes hidden structures which affect their classroom practice. Once again, this implies that SITE must support and prepare pre-service teachers to develop a comprehensive understanding of their own epistemological (Kim and Nehm 2011), scientific (Hipkins, Barker and Bolstad 2005) and cultural (Milner 2010) beliefs since these have a significant impact on their classroom practice. SITE must also help foster the construction of teachers' pedagogical judgements and their personal sensitivity towards cultural (super) diversity so as to consider and resolve fundamental belief conflicts that may appear in the classroom (Gay 2010).

Furthermore, SITE must re-evaluate its existential position regarding the nature of science education in a superdiverse world: what is SITE about? What is its purpose? What is SITE trying to achieve with its pre-service teachers? And what other approaches can we employ to support pre-service teachers' teaching in superdiverse communities?

These are all necessary questions that science teacher educators must now ask in order to help preservice teachers cope with multi-religious views within the science classroom. SITE must enable preservice teachers to become more reflective and critical about the place of students' worldviews within the science classroom and involve them in developing strategies to effectively help "students manage their personal beliefs in relation to [Science], rather than attempt to [completely] change them" (Meadows, Doster and Jackson in Hanley, Bennett and Ratcliffe 2014, p. 1212) because the religious practices and beliefs of students are a critical and integral part of who they are, it is how they also express their identity and who they are as a person (Fysh and Lucas 1998). Critically, school students' abilities to navigate between science, diverse cultures and religious practices as well as their ability to resolve conflicting beliefs are not well established (Aikenhead and Jegede 1999). Thus, science teachers play an important role in managing views and beliefs in order to allow them to share meaningful science learning experiences within the classroom.

However, a comprehensive standardisation of pedagogical strategies across the teaching of science is unrealistic and undesirable because teaching is a social profession that entails an appreciation for diversity and multimodality of practice. Each school and each science classroom will need a different approach. Therefore, as science teachers prepare to encounter students with a myriad of worldviews about science, religion and other intrinsic cultural facets, they must be explicitly educated to manage and tailor meaningful learning episodes which will help to avoid creating confusion and conflict while at the same time promoting student reflection and discussion about science, including topics which may be considered controversial. Science Teacher Educators, pre- 
service and practicing teachers can be supported by existing work, such as materials promoted by the Bio-ethics and Physics Education Projects and the Science and Religion in Schools' Project. At the same time, support may also be provided by local teachers to support the local context of their students in cross-curricular ventures.

This essentially means that there is a need for a change of paradigm within SITE. It must address these religious-cultural issues head-on and clearly identify the challenges that pre-service teachers are likely to face within large urban environments. It can no longer ignore the superdiverse society of large metropolitan areas. It is imperative that SITE assembles and develops a set of satisfactory arguments towards a larger appreciation of this type of understanding within science education because that would allow future science teachers to respond "more flexibly to all encounters with [students'] culture in its broadest sense" (Kai 2003, p. 33 in Vertovec 2006, p. 29).

My own account of my school experience as a science teacher (De Carvalho 2013) is an example of a possible classroom activity which attempts to encompass the dynamic between scientific evidence and faith when teaching about the Big Bang theory. Without focusing on specific religious beliefs, I attempted to engage my students in the broadest sense of both religio-cultural worldview and science. The result was a better appreciation of the dichotomies between faith and the meaning of evidence in science. The flexibility of the task allowed students to pursue different avenues based on their own interest as well as having to openly discuss the meaning of scientific theory, evidence and the Big Bang. This example is certainly not the only one. Trani (2004) exposed the difficulties within the American context with the varied disagreement between biologists, biology teachers and laypeople while Nancy Brickhouse, Zoubeida Dagher, William Letts and Harry Shipman (2000) and Harry Shipman, Brickhouse, Dagher and Letts (2002) have explored students' interactions between the nature of scientific understanding and religion in the context of an Astronomy course, concluding that the issue must be approached sensitively and appropriately in order to benefit students and promote a meaningful understanding of science. In addition, Reiss (2008) has considered and described some of the pedagogical issues involved if the science/religion issue is to be debated in the science classroom if and when it appears. Reiss (2011) also discussed at length the epistemic problems of addressing and teaching challenging scientific issues in light of creationism and intelligent design, with both texts providing a range of other relevant literature.

In the long run, science teachers and teacher educators must ask themselves how students with religious beliefs engage with learning about science, and whether they are learning real science or whether they are "simply learning a set of definitions, or a wellrehearsed narrative, and reproducing it as accurately as possible?" (Ferguson and Kameniar 2014, p. 6). In order to revise our practice, SITE educators must first understand and frame the ways in which both teachers and students may relate and deal with religioscientific ideas.

\section{Framing religio-scientific understanding}

There have been attempts at mapping and framing of schemas for both students' and teachers' religio-scientific ideas (e.g. Stolberg 2007). Two of the latest and important work, those of Pam Hanley, Judith Bennett and Mary Ratcliffe (2014) and Ferguson and Kameniar (2014), have both tackled the idea in an innovative and useful way, drawing on different analytical and theoretical frameworks. In this paper, I draw on Hanley, Bennett and Ratcliffe and their conceptual framework focusing on "facilitating border crossings from students' everyday world into the school 
environment ... [which] explores how to manage any incompatibilities while allowing students to maintain respect for their home culture" (2014, p. 1214). The conceptualisation of 'bordercrossing' theory is an essential pre-requisite for science teachers within superdiverse classrooms because their understanding and respect towards students' multi-religious backgrounds will help to facilitate their navigation through some of the differences between science and religion (Aikenhead 2001). Conversely, conceptual change theory focuses on knowledge replacement through conceptual challenge (Sinatra, Southerland, McConaughy and Demastes 2003) in addition to emphasising the acquisition of knowledge, but consistent conceptual change is unlikely to happen in the short period of time available to science teachers in schools. Science teachers of classrooms with multireligious backgrounds are likely to encounter resistance if they insist on forcefully pushing a higher status to science in direct opposition to religious beliefs of their students. Thus, the negotiation of meaning becomes a vital skill for the science teacher to learn during their training.

The religio-scientific beliefs of newer generations of students may be more likely to be influenced and challenged by the new multimodality of knowledge and the never-ending presence of sciencerelated advances in technology, medicine and other fields, while at the same time having to deal with the reality of a religious family life. Therefore, if teachers adopt an extreme Dawkinsian view of science and directly antagonise students' religious views, they would be actively dismissing a student's cultural heritage. On the other hand, this could become a very problematic stance since it is context-dependent as different cultural norms believe and act in different ways. It is paramount that any teacher argues against any form of culturally-related prejudice towards anyone which may emerge in any scenario within the science classroom. Teachers must be attentive to radical views which may ignite other types of conflicts in the classroom and challenge them when necessary. Yet, when discussing the approach between science and religion teachers also "need to recognise that the goal is not to convince students of which worldview is correct but to examine the available evidence without condemning a student's existing [religious] worldview" (Hanley, Bennett and Ratcliffe 2014, p. 1226). Nevertheless, this will only become possible if SITE and pre-service teachers and their mentors are prepared to engage with this issue in order to better prepare future teachers. It is in the development of the understanding by pre-service teachers and SITE educators that Hanley, Bennett and Ratcliffe's work becomes invaluable.

Hanley, Bennett and Ratcliffe studied students of different faiths as well as non-believers in four different schools in the UK. This allowed them to develop a 'typology of engagement' between science and religion that "divides students into categories depending on both the nature and amount of engagement they were prepared to have with the relationships between science and religion" (2014, p. 1210). Their typology works as an explanatory tool that was designed to provide a way to elucidate the myriad of complex student positions around the issue and, most importantly, "it is not designed to be hierarchical, favouring one specific type over another" (Hanley, Bennett and Ratcliffe 2014, p. 1222). In modern, large-scale and superdiverse urban centres, abounding with multilinguism and multiculturalism, this is a vital stance. Tolerance, empathy and sensitivity towards controversial issues are characteristics which must also be present in the science classroom and modelled by the science teacher, albeit with a clear stance on the meaning of scientific evidence and how science and religion operate in divergent "frames of reference" (Mezirow 2009) and are different pathways towards the construction of meaning in both informational and transformational learning (Kegan 2009). This is further corroborated by William Cobern and Cathleen Loving (2001) when they explain that: 
science can be defined with sufficient clarity so as to maintain a coherent boundary for the practical purposes of school science curriculum development. That boundary excludes most forms of indigenous knowledge, if not all, just as it excludes art, history, economics, religion, and many other domains of knowledge. Being exclusive, however, does not confer science with any privilege vis-a ${ }^{`}$-vis other domains. Science is properly privileged only within its own domain for that is where its strength lies.

(pp. 64-65)

Ian Barbour's (1990) taxonomy is an early attempt to frame religio-scientific understanding but as it has a strong classification and an almost hierarchical outline. I would argue that it may not be suitable to deal with a more superdiverse society since his "four types of science-religion relationships are not fundamental but highly localised constructions. It is like classifying a number of objects according to shape when the physically relevant parameter is colour"' (Cantor and Kenny 2001, p. 778).

On the other hand, Hanley, Bennett and Ratcliffe's framework appears to provide a bigger scope for interpreting and managing people's relationship between science and religion. Although their typology was developed mainly with school students, pre-service teachers, teachers and science teacher-educators may also fall within the model presented, albeit with different levels of scientific, religious and epistemological understanding. With four bipolar dimensions (see Fig. 1), but with each having their own relationships, it specifies a more humanistic typology of how students may engage with each set of dimensions.

Dimension 1: foundation of knowledge

fact

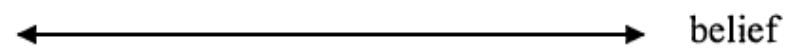

Dimension 2: tolerance of uncertainty need resolution accept discomfort

Dimension 3: open-mindedness unquestioning $\longleftrightarrow$ inquiring

Dimension 4: Nature of science/religion relationship competitive $\longleftrightarrow$ in harmony

Fig. 1 Four dimensions characterising the engagement typology (taken from Hanley, Bennett and Ratcliffe 2014, p. 1218)

This framework attempts to identify the existence of a continuum within boundaries where students and teachers have to work and exchange meaning. Since it is non-hierarchical and provides a continuum of positions within each dimension, it allows for an important and relatively safe 
discussion space within a superdiverse science classroom. Hanley, Bennett and Ratcliffe's research also suggests that teachers failed to appreciate the level of difficulty some students have in order to face and accommodate key ideas between science and their religious beliefs. Additionally, George Posner et al.'s (1982) work on a theory of conceptual change may lead science educators to believe that because teachers may be presenting 'strong' scientific evidence, how can students not 'believe' in science?

Although, conceptual change involves both revolutionary as well as evolutionary components (Ozdemir and Clark 2007), this process when confronted with religious beliefs takes a whole different meaning as the conflict happens on frameworks which are incompatible, one which relies on 'faith' and another which relies on 'scientific evidence'. As such, it becomes apparent that there must be an increased understanding of the level of complexity present in students' beliefs (Hanley, Bennett and Ratcliffe 2014) and how this relates to students' scientific understanding. This means that SITE must raise its own level of awareness and thus improve the guidance and training of science teachers towards a more sensitive and suitable approach when covering controversial topics such as the origins of the universe and the evolution of organisms.

\section{Science pedagogy and practice for a superdiverse society}

Bernstein (1971, p. 47) defined pedagogy as "what counts as valid transmission of knowledge" and more recently Annette Woods and Allan Luke (2012, p. 313) have used the term innovative pedagogy to "relate to change in teaching practice, as an alteration in the social relations of knowledge constructions and production by teachers and students". In these times of superdiversity in our large urban and metropolitan areas, it is time to look at the framing and boundaries of pedagogy and use these to inform a pedagogy for superdiversity.

A pedagogy where:

the knowledge from one or more academic subjects is embedded within another; students are required to call on the skills, process and understandings of a variety of school subject areas to complete a task or activity; and the boundaries between these school subjects or disciplines are less visible to learners.

(Woods and Luke 2012, p. 314)

SITE is well placed within the school curriculum to lead a breakdown of subject boundaries, especially between physics, biology and chemistry. SITE must foster a pedagogy which embraces thinking about the teaching behind the methods used in teaching. It must foster a science pedagogy for superdiversity which is informed by a meaningful understanding of the epistemology of science and the interdependent nature of science with the world we live in; and thus, how that impacts teaching and learning in the classroom. This implies that more time must be devoted to the thinking behind the practice of school science so that the confusion between pedagogy and teaching methods is clarified, allowing pre-service teachers to better understand the choices they make while planning a learning episode. This is especially important when dealing with more nuanced science topics which may be perceived as challenging or controversial by students with strong religious beliefs within a superdiverse school environment. 
Further still, I argue for a pedagogical shift within science teaching towards a more thoughtful rationalisation of science, moving away from a focus on methods and the ideal of 'imparting' scientific knowledge and facts, which is likely to alienate most students in science classrooms due to the over-emphasis on worksheets, slide presentations as well as the constant misuse of science investigations (SCORE 2008). Science teachers can promote a pedagogy for superdiversity by emphasising the processes of science and their importance to the progress of our societies. Understanding the meaning of science and how it operates may be a way to re-frame science pedagogy as an integral part of the curriculum rather than framing it around the content knowledge itself and how to deliver it. It is also imperative to say that if, and when the chance arises, science "teachers should make use of the opportunity to give students an insight into the nature of science and religion, how the media present the relationships between science and religion and how they are presented in scholarship" (Billingsley, Riga, Taber and Newdick 2014, p. 391).

Nevertheless, there are still many questions that remain unanswered as to whether pedagogical understanding directly influences teachers' planning of lessons and classroom practice and whether more 'instinctive' actions or reactions during practice actually influence their pedagogical discourse and future behaviour (Pajares 1992). Currently, in England, there is an intentional move to focus Initial Teacher Education mainly on on-thejob classroom practice with little time for pre-service teachers to develop a more meaningful awareness of both pedagogy and psychology of education. As present in the rhetoric of the Department for Education's Schools White Paper The Importance of Teaching (implemented in 2012 through the new School Direct programme):

The best education systems in the world draw their teachers from among the top graduates and train them rigorously and effectively, focusing on classroom practice ... (p. 9) ... Too little teacher training takes place on the job, and too much professional development involves compliance with bureaucratic initiatives rather than working with other teachers to develop effective practice. (p. 21)

(DfE 2010, my italics)

Although a significant amount of relevant classroom practice is essential to new teachers' development, the move towards on-the-job training comes to the detriment of pre-service teachers' time to be dedicated towards the development of meaningful pedagogical understanding. The 'traditional' secondary Initial Teacher Education courses in England (i.e. PGCE-Post-Graduate Certificate in Education) are only 9 months long, with $1 / 3$ spent at university-one of the shortest in Europe-and 2/3 spent in schools on classroom-based learning-one of the longest in Europe (Eurydice 2013). As can be inferred, there are significant time constraints on teacher development in England. Thus, SITE has to rely on pre-service teachers' self-reflection and self-evaluation of their practice which, albeit extremely important, invariably tends to relate more to the mechanics of the practice itself (i.e. what was 'good' and what was 'not-so-good' during the lesson and what should I do to change it?) instead of discussing why it was good/not-so-good and how a decision was made for specific tasks and why changing it may be important. It also relies on school mentors' own knowledge and understanding of teaching and learning which is likely to be similarly focused on what works in their classroom and what leads to a measurable outcome rather than a coherent grasp of the nature of science epistemology and pedagogy, and how this guides their decisionmaking for a better teaching and learning experience. Further still, within our institution we have a 
large amount of anecdotal evidence that formal discussions between mentors and pre-service teachers in school is variable in both length and quality. Evidence from pre-service teachers' logbooks shows that targets given by mentors at school are usually related to the actual mechanics of the classroom and the practicalities of the course rather than promoting a deeper development of ideas about the entire teaching and learning process.

Thus, in England, in order to nurture further understanding of a new science pedagogy in a superdiverse environment, the mentoring routine must become a more thoughtful development of teachers' pedagogical knowledge and understanding through asking more pertinent questions about what would account for the rationale behind pre-service teachers' choices and structures for the lesson as well as the consequences to students' learning. This requires a more meaningful mentor training regime, partnership schools must provide more time for mentors to reflect and support preservice teachers as well as include some form of recognition for their investment in the training of pre-service teachers.

However, given high-stakes examinations within the English system, many science teachers outline their practice according to pressures from senior management teams, the government and OFSTED; and this often falls within the requirement to teach what will 'be in the exam', with students following recipes for practical work (SCORE 2008) and turning science lessons into a systematic routine of 'fact-finding' and 'exam questions', completely disregarding other potentially relevant thinking skills and different forms of knowledge and understanding. "This 'playing safe' means that certain aspects of learning and development might be emphasised at the expense of fostering a shift to the discomfort and inquiry ends of the above dimensions" (Hanley, Bennett and Ratcliffe 2014, p. 1223). Furthermore, although the change towards a more school-based SITE may have led to a sense of improvement in the quality of classroom practice, there is a growing concern from the

overwhelming dominance for [achieving the teaching] 'standards' (Department for Education and Skills 2002; Furlong et al. 2000) as a way of thinking about quality in ITE, and a consequent neglect of the ITE curriculum and of the quality of student teachers' learning experiences ... [and] the simplistic and entirely untheorized understanding of classroom teaching competence [,practice] and expertise that informs these 'standards'.

(Hagger and McIntyre 2006, p. 17)

Finally, Burton (2008) notes that "if the fundamental thrust of education is 'being correct' rather than acquiring a thoughtful awareness of ambiguities, inconsistencies, and underlying paradoxes, it is easy to see how the brain reward systems might be moulded to prefer certainty over openmindedness" (p. 99, in Hanley, Bennett and Ratcliffe 2014, p. 1223).

\section{Further implications for science initial teacher education}

Throughout the text I have attempted to engage the reader in several arguments related to the issues which our science teachers are facing within schools in superdiverse constituencies. I have attempted to promote a coherent narrative that made explicit links between science teacher 
educators, science pre-service teachers, science teachers and students in our superdiverse classrooms. I have also argued for a re-think of SITE within the context of superdiversity and how those involved in science education should be more explicitly aware of their own epistemological understanding of science as a way of building knowledge and as a worldview as well as developing their own religious understanding including how faith is operationalised within specific worldviews. I have discussed certain issues which SITE must address in order to support science teachers in their superdiverse classrooms, especially on how science pedagogy is re-conceptualised in a new pedagogy for superdiversity. This is paramount because science teachers must have a clear picture of the scientific epistemological framework on which concepts such as Evolution and Big Bang are built on so as to convey ideas which are scientifically accurate without undermining students' worldviews. At the same time, science teachers and their students must understand that 'being [scientifically] correct' is fundamentally different than 'being religiously correct'.

Remarkably, it may be that the new knowledge infrastructure, such as the internet and pop culture, that is able to give the science vs religion debate a new life as it clearly informs our students' way of living as well as it brings forward a necessary change to the access to knowledge. Since both science and religion have similar yet different sociolinguistic and cultural roles, these border-crossing developments allow science teaching pedagogies and strategies to be re-analysed and re-interpreted for the new superdiverse science classroom.

Therefore, SITE must foster a "critical sociolinguistics of diversity" (Arnaut 2012, p. 10) within science education where it must pursue a more sustained critical analysis of its own hegemonic discourse in order to address the way superdiversity engages with scientific knowledge. As Karel Arnout writes, the critical sociolinguistics of diversity's

espousal of unpredictability is culturally critical in that it wipes away the false certainties of how, or the lines within, people construct meaning in interaction. It is critical in the sense of counterhegemonic in that it destabilises established systems of difference or regimes of diversity.

(2012, p.12)

Thus, science teacher educators must enable formal discussions within their programmes so as to do away with the idea that 'science trumps religion' since the reality of the science classroom is a confluence of worldviews which must not be ignored, especially when teaching science topics which may be considered controversial by students with strongly held views about religion and the world. It is by carefully managing expectations and clearly articulating the meaning of science and its influence in the world we live that we can develop our students' understanding of science and how it operates.

This implies that SITE itself, especially in those institutions in superdiverse constituencies, must find ways to engage pre-service teachers in more meaningful discussions about the varied worldviews relating to science, culture and religion their students are likely to have. SITE must help pre-service teachers in understanding the nature of science and how to support the questioning by their students of conflicting ideas between science and religion (Reiss 2008). Science teacher educators must themselves be more aware of their own uses of language and the meanings of science, 
scientific evidence, faith and religion in order to be empowered to prepare and make pre-service teachers fully aware of the superdiverse views they are about to encounter (Mansour 2008).

Rather importantly, this position paper is not about learning specific religious doctrines within science education. Instead, it is about the need for science teacher educators and science preservice teachers to develop a meaningful understanding of faith and how students interact with their cultural and religious knowledge in light of scientific knowledge and evidence, and what it means to them. In order to support this, science educators must also be able to have a good conceptual understanding of their own views about the nature and epistemology of science and recognise that this deeply influences preservice teachers' own pedagogical beliefs and practices in science lessons since "our behaviours, beliefs, and attitudes, our preparation in science and religion, and the support we receive to promote and teach our courses have an important influence on student outcomes" (Nyhof-Young 2000, p. 442 in Mansour 2008, p. 573).

In a multi-religious science classroom in a superdiverse society, it is necessary to think how science is going to be taught to students and how they will interact with it. And, as expressed before, it is paramount that students emerge from schools with a better grasp of the differences between the nature of science and religion in a non-confrontational way. This could, potentially, make a significant contribution to a more harmonious co-existence between religion and science within the classroom with the outlook of attracting and recruiting students who would not otherwise pursue science as a career. This approach could also potentially contribute to greater tolerance within our superdiverse communities.

In light of this discussion of superdiversity in the SITE and the science classroom, and since "many prospective teachers do not think deeply about their attitudes and beliefs towards ethnic, cultural and racial diversity; some deliberately resist doing so" (Gay 2010, p. 145), teacher selection for SITE courses in major constituencies that cater for our superdiverse classrooms must begin to think about identifying (and developing) people with certain characteristics that go beyond the mastery of subject knowledge or communication skills. These teachers' dispositions are valuable assets that must, somehow, be assessed when selecting potential pre-service teachers and teachers (Wasicsko Wirtz and Resor 2009) and encouraged during their training. Nieto (2005, in Gay 2010) presents a selection of five attitudinal qualities present in teachers that tend to promote cultural diversity:

They are

1. a sense of mission to serve ethnically diverse children to the best of their abilities

2. solidarity with, empathy for, and value of students' lives, experiences, cultures, and human dignity

3. courage to question mainstream school knowledge and conventional ways of doing things, and beliefs and assumption about diverse students, families, cultures and communities

4. willingness to improvise, push the envelope, to go beyond the established templates and frameworks, and to embrace uncertainty and flexibility; and

5. a passion for equality and social justice 
The cultivation of these attitudes could constitute the core of teacher education programs devoted to developing beliefs that are ideological anchors for incorporating cultural, [and religious super-] diversity into teaching behaviours.

(Gay 2010, p. 145)

\section{Final remarks}

This paper is the starting point of my own research project with science teacher educators. It is the first in a series of papers that will attempt to capture views and understandings on the nature of science as well as cultural and religio-scientific issues alongside their views on the place of these issues within science teacher education and the science classroom. Pre-service teachers will also be interviewed so as to enable me to understand their expectations on teaching science in a highly superdiverse community with multi-religious views and how to best approach the issues as a science teacher.

Ultimately, the question for science teacher educators remains: how to assist pre-service teachers in moving beyond the learning of/about science towards a more significant engagement with the notion that once in the classroom they will be teaching students with a range of worldviews and religious beliefs. We want our students to have a meaningful understanding of what science is, how it works and how it has helped the world to move forward. We want them to engage with science in a meaningful way, regardless of their cultural backgrounds or religious belief. And we want our science teachers to feel confident and to be able to engage in such discussions. This is because in order to become highly effective teachers, they must become more positive, reflective and contextually responsive (Kingston, Day, Simmons, Regan, Brown and Gunraj 2012) towards superdiversity in the globalised world and it is our job as science teacher educators to support them in this journey.

\section{References}

Aikenhead, G. S. (1996). Science education: Border crossing into the subculture of science. Studies in Science Education, 27(1), 1-52. doi:10.1080/03057269608560077.

Aikenhead, G. S. (2001). Students' ease in crossing cultural borders in school science. Science Education, 85(2), 180-188. doi:10.1002/1098-237X(200103)85:2\180:AID-SCE50[3.0.CO;2-1.

Aikenhead, G. S., \& Jegede, O. (1999). Cross-cultural science education: A cognitive explanation of a cultural phenomenon. Journal of Research in Science Teaching, 36(3), 269-287. doi:10.1002/ (SICI)1098-2736(199903)36:3\269:AID-TEA3[3.0.CO;2T.

Alsop, S. (2005). Beyond cartesian dualism: Encountering affect in the teaching and learning of science. Dordrecht: Springer. doi:10.1007/1-4020-3808-9_1.

Arnaut, K. (2012). Super-diversity: Elements of an emerging perspective. Diversities, 14(2), 1-15. Barbour, I. G. (1990). Religion in an age of science. London: SCM.

Bausor, J., \& Poole, M. (2003). Science and religion in the agreed syllabuses -an investigation and some suggestions. British Journal of Religious Education, 25(1), 18-32.

doi:10.1080/0141620020250103- >. 
BBC (2008). Tests 'damaging' to school system. BBC News online. Retrieved from http://news.bbc.co.uk/1/ hi/education/7396623.stm Accessed 24 May 2014.

Bernstein, B. (1971). On the classification and framing of educational knowledge. In M. Young (Ed.), Knowledge and control: New directions for the sociology of education (pp. 47-69). London: Collier Macmillan.

Billingsley, B., Riga, F., Taber, K. S., \& Newdick, H. (2014). Secondary school teachers' perspectives on teaching about topics that bridge science and religion. The Curriculum Journal, 25(3), 372-395. doi:10.1080/09585176.2014.920264.

Brickhouse, N., Dagher, Z., Letts, I., William, J., \& Shipman, H. (2000). Diversity of students' views about evidence, theory, and the interface between science and religion in an astronomy course. Journal of Research in Science Teaching, 37(4), 340-362. doi:10.1002/(SICI)1098-

2736(200004)37:4\340:AIDTEA4[3.0.CO;2-D.

Cantor, G., \& Kenny, C. (2001). Barbour's fourfold way: Problems with his taxonomy of sciencereligion relationships. Zygon, 36(4), 765-781. doi:10.1111/0591-2385.00395.

Clement, P., Quessada, M., Laurent, C. and Carvalho, G. (2008). Science and religion: evolutionism and creationism in education: a survey of teachers conceptions in 14 countries. (online) Paper presented at: XIII IOSTE Symposium, Izmir (Turkey), 21-26 September 2008. Retrieved from http://repositorium. sdum.uminho.pt/bitstream/1822/8934/1/IOSTE_Evolution.pdf Accessed 27 May 2014.

Cobern, W., \& Loving, C. (2001). Defining" science" in a multicultural world: Implications for science education. Science Education, 85(1), 50-67. doi:10.1002/1098-237X(200101)85:1 \50:AID-SCE5[3. $0 . \mathrm{CO} ; 2-\mathrm{G}$.

Collins, S. and Reiss, M. and Stobart, G. (2009) The effects of national testing in science at Key Stage 2 in England and Wales. Executive Summary. Commissioned by The Wellcome Trust in association with the ASE. Retrieved from http://www.wellcome.ac.uk/stellent/groups/corporatesite/@msh_peda/ documents/web_document/wtd039972.pdf Accessed 20 May 2014.

Dagher, Z., \& BouJaoude, S. (1997). Scientific views and religious beliefs of college students: The case of biological evolution. Journal of Research in Science Teaching, 34(5), 429-445. doi:10.1002/ (SICI)1098-2736(199705)34:5\429:AID-TEA2[3.0.CO;2-S.

Dawkins, R. (2006). The god delusion (1st ed.). Boston: Houghton Mifflin Co.

De Carvalho, R. (2013). The Big Bang theory-coping with multi-religious beliefs in the super-diverse science classroom. School Science Review, 95(350), 119-126.

De Saint-Georges, I. (2013). Multilingualism, multimodality and the future of education research. In De Saint-Georges, I., \& Weber, J-J. (Eds.), Multilingualism and multimodality: Current challenges for educational studies (pp. 1-8). New York: Springer. http://dx.doi.org/10.1007/978-94-6209-266-2. 
DfE (Department for Education) (2010). The schools' white paper 2010-the importance of teaching. London: Department for Education. Retrieved from

https://www.gov.uk/government/uploads/system/ uploads/attachment_data/file/175429/CM7980.pdf Accessed 23 May 2014.

DfE (Department for Education) (2013). Science-GCSE content and assessment objectives. London: Department for Education. Retrieved from

https://www.gov.uk/government/uploads/system/uploads/

attachment_data/file/211219/GCSE_Sciences_final_updated.pdf Accessed 23 May 2014.

Dodick, J., Dayan, A., \& Orion, N. (2010). Philosophical approaches of religious Jewish science teachers toward the teaching of 'controversial' topics in science. International Journal of Science Education, 32(11), 1521-1548. doi:10.1080/09500690903518060.

Downie, R. J., \& Barron, N. J. (2000). Evolution and religion: Attitudes of Scottish first year biology and medical students to the teaching of evolutionary biology. Journal of Biological Education, 34(3), 139-146. doi:10.1080/00219266.2000.9655704.

El-Hani, C., \& Sepulveda, C. (2010). The relationships between science and religion in the education of protestant biology preservice teachers in a Brazilian university. Cultural Studies of Science Education, 5(1), 103-125. doi:10.1007/s11422-009-9212-7.

Eurydice (2013). Key data on teachers and school leaders in Europe. 2013 Edition. Eurydice Report. Luxembourg: Publications Office of the European Union.

Ferguson, J., \& Kameniar, B. (2014). Is 'learning' science enough? A cultural model of religious students of science in an Australian government school. International Journal of Science Education, Published online on 1st April 2014, 1-26. Retrieved from http://www.tandfonline.com/doi/full/10.1080/ 09500693.2014.904060\#tabModule Accessed 21 May 2014. doi.org/10.1080/09500693.2014.904060.

Fysh, R., \& Lucas, K. (1998). Religious beliefs in science classrooms. Research in Science Education, 28(4), 399-427. Gay, G. (2010). Acting on beliefs in teacher education for cultural diversity. Journal of Teacher Education, 61(1-2), 143-152. doi:10.1177/0022487109347320.

Gogolin, I. (2011). The challenge of super diversity for education in Europe. Education Inquiry, 2(2), 239-249. doi:10.3402/edui.v2i2.21976.

Gove, M. (2013) Speech: Michael Gove speaks about the importance of teaching. Retrieved from https:// www.gov.uk/government/speeches/michael-gove-speaks-about-the-importance-ofteaching Accessed 20 May 2014.

Hagger, H., \& McIntyre, D. (2006). Learning about teaching from teachers. Maidenhead: Open University Press.

Hanley, P., Bennett, J., \& Ratcliffe, M. (2014). The Inter-relationships of science and religion: A typology of engagement. International Journal of Science Education, 36(7), 1210-1229.

doi:10.1080/09500693. 2013.853897. 
Hipkins, R., Barker, M., \& Bolstad, R. (2005). Teaching the 'nature of science': Modest adaptations or radical reconceptions? International Journal of Science Education, 27(2), 243-254. doi:10.1080/ 0950069042000276758.

Kegan, R. (2009). What 'form' transforms? A constructive-developmental approach to transformative learning. In K. Illeris (Ed.), Contemporary theories of learning: Learning theorists... in their own words (pp. 35-52). London: Routledge.

Kingston, A., Day, C., Simmons, P., Regan, E., Brown, E., \& Gunraj, J. (2012). What makes teachers effective? Profiles of innovative classroom practice. In C. Day (Ed.), The routeldge international handbook of teacher and school development (1st ed., pp. 319-334). Abingdon, Oxon: Routeldge.

Kim, S. Y., \& Nehm, R. H. (2011). A cross-cultural comparison of Korean and American science teachers' views of evolution and the nature of science. International Journal of Science Education, 33(2), 197-227. doi:10.1080/09500690903563819.

Liu, S., \& Lederman, N. (2007). Exploring prospective teachers' worldviews and conceptions of nature of science. International Journal of Science Education, 29(10), 1281-1307. doi:10.1080/ 09500690601140019.

Loving, C., \& Foster, A. (2000). The religion-in-the-science-classroom issue: Seeking graduate student conceptual change. Science Education, 84(4), 445-468. doi:10.1002/1098-237X(200007)84:4\445: AID-SCE2[3.0.CO;2-6.

Mansour, N. (2008). Religious beliefs: A hidden variable in the performance of science teachers in the classroom. European Educational Research Journal, 7(4), 557-576. doi:10.2304/eerj.2008.7.4.557.

Mansour, N. (2011). Science teachers' views of science and religion vs. the Islamic perspective: Conflicting or compatible? Science Education, 95(2), 281-309. doi:10.1002/sce.20418.

Martin-Hansen, L. (2008). First-year college students' conflict with religion and science. Science \& Education, 17(4), 317-357. doi:10.1007/s11191-006-9039-5.

Mezirow, J. (2009). An overview on transformative learning. In K. Illeris (Ed.), Contemporary theories of learning: Learning theorists ... in their own words (pp. 90-105). London: Routledge.

Millar, R., \& Abrahams, I. (2009). Practical work: Making it more effective. School Science Review, 91(334), 59-64.

Milner, H. (2010). What does teacher education have to do with teaching? Implications for diversity studies. Journal of Teacher Education, 61(1-2), 118-131. doi:10.1177/0022487109347670.

Newton, D. P. (1988). Making science education relevant. London: Kogan Page Ltd. OFSTED, (2013). Ofsted | Maintaining curiosity: A survey into science education in schools. (online). Retrieved from: http://www.ofsted.gov.uk/resources/maintaining-curiosity-survey-science-educationschools Accessed 21 May 2014. 
Ozdemir, G., \& Clark, D. (2007). An overview of conceptual change theories. Eurasia Journal of Mathematics, Science and Technology Education, 3(4), 351-361.

Pajares, M. F. (1992). Teachers' beliefs and education research: Cleaning up a messy construct. Review of Education Research, 62(3), 307-332. doi:10.3102/00346543062003307.

Phelan, P., Davidson, A. L., \& Cao, H. T. (1991). Students' multiple worlds: Negotiating the boundaries of family, peer and school cultures. Anthropology and Education Quarterly, 22, 224-250. doi:10.1525/ aeq.1991.22.3.05x1051k.

Posner, G., Strike, K., Hewson, P., \& Gertzog, W. (1982). Accommodation of a scientific conception: Toward a theory of conceptual change. Science Education, 66(2), 211-227. doi:10.1002/sce. 3730660207.

Reiss, M. (2008). Should science educators deal with the science/religion issue? Studies in Science Education, 44(2), 157-186. doi:10.1080/03057260802264214.

Reiss, M. (2011). How should creationism and intelligent design be dealt with in the classroom? Journal of Philosophy of Education, 45(3), 399-415. doi:10.1111/j.1467-9752.2011.00790.x.

Roth, W. (1997). The interaction of students' scientific and religious discourses: Two case studies. International Journal of Science Education, 19(2), 125-146. doi:10.1080/0950069970190201. SCORE (2008) Practical work in science: A report and proposal for a strategic framework. Science community representing education report. December 2008. Retrieved from http://scoreeducation.org/ media/3668/report.pdf Accessed 20 May 2014.

Shepherd, J. (2010, August 13). Pupils do better at school if teachers are not fixated on test results. The Guardian online. Retrieved from http://www.theguardian.com/education/2010/aug/13/examtestresults-teaching-style Accessed 25 May 2014.

Shipman, H., Brickhouse, N., Dagher, Z., \& Letts, W. (2002). Changes in student views of religion and science in a college astronomy course. Science Education, 86(4), 526-547. doi:10.1002/sce.1002.

Sinatra, G. M., Southerland, S. A., McConaughy, F., \& Demastes, J. W. (2003). Intentions and beliefs in students' understanding and acceptance of biological evolution. Journal of Reseach in Science Teaching, 40, 510-528. doi:10.1002/tea.10087.

Stolberg, T. (2007). The Religio-scientific frameworks of pre-service primary teachers: An analysis of their influence on their teaching of science. International Journal of Science Education, 29(7), 909930. doi:10.1080/09500690600924934.

Sutherland, D., \& Dennick, R. (2002). Exploring culture, language and the perception of the nature of science. International Journal of Science Education, 24(1), 1-25. doi:10.1080/09500690110067011.

Taber, K., Billingsley, B., Riga, F., \& Newdick, H. (2011). Secondary students' responses to perceptions of the relationships between science and religion: Stances identified from an interview study.

Science Education, 95(6), 1000-1025. doi:10.1002/sce.20459. 
The Guardian (2006, July 20). Too many teachers 'teaching to the test'. The Guardian Online. Retrieved from http://www.theguardian.com/education/2006/jul/20/schools.uk5 Accessed 23 May 2014.

The Telegraph (2008). Ofsted: Schools 'teaching to the test'. The Telegraph online. Retrieved from http:// www.telegraph.co.uk/education/2440091/Ofsted-Schools-teaching-to-the-test.html Accessed 22 May 2014.

The telegraph (2010). Sats exams promote 'teaching to the test'. The Telegraph online. Retrieved from http://www.telegraph.co.uk/education/educationnews/7559726/Sats-exams-promoteteaching-to-thetest.html Accessed 24 May 2014.

Trani, R. (2004). I won't teach evolution. It's against my religion. And now for the rest of the story. The American Biology Teacher, 66(6), 419-427. doi:10.2307/4451708.

Vertovec, S. (2006). The emergence of super-diversity in Britain. Centre on migration, policy and society - working paper No 25. COMPAS - University of Oxford. Retrieved from https://www.compas.ox.ac.uk/ fileadmin/files/Publications/working_papers/WP_2006/WP0625_Vertovec.pdf Accessed 26 May 2014.

Vertovec, S. (2007). Super-diversity and its implications. Ethnic and racial studies, 30(6), 1024-1054. doi:10.1080/01419870701599465.

Von Ahn, M.,Lupton, R.,Greenwood, C., \& Wiggins, D. (2010). Languages, ethnicities and education in London. DoQSS working paper No.10-12. Department of Quantitative Social Science, Institute of Education, University of London. Retrieved from http://repec.ioe.ac.uk/REPEc/pdf/qsswp1012.pdf Accessed 20 May 2014.

Waldrip, B. G., Timothy, J. T., \& Wilikai, W. (2007). Pedagogic principles in negotiating cultural conflict: A melanesian example. International Journal of Science Education, 29(1), 101-122. doi:10.1080/ 09500690600718195.

Wasicsko, M. M., Wirtz, P., \& Resor, C. (2009). Using dispositions in the teacher admission process. SRATE Journal, 18(2), 19-26.

Wellington, J., \& Osborne, J. (2001). Language and literacy in science education (1st ed.). Buckingham: Open University.

Woods, A., \& Luke, A. (2012). Innovative pedagogies. In C. Day (Ed.), The Routledge International Handbook of Teacher and School Development (1st ed., pp. 313-318). Abingdon, Oxon: Routledge.

Yasri, P., \& Mancy, R. (2014). Understanding student approaches to learning evolution in the context of their perceptions of the relationships between science and religion. International Journal of Science Education, 36(1), 24-45. doi:10.1080/09500693.2012.715315.

Roussel De Carvalho taught Physics at secondary schools for over 11 years and has worked with Science Initial Teacher Education since 2012. He is a Lecturer in Science Education at UCL Institute of Education in London. His research focuses on superdiversity issues in the science classroom; gender 
and underrepresented minority groups in science education; science teaching pedagogy and multimodality; and teacher selection. 